\title{
What Happened to MSMEs During the Pandemic?
}

The Covid-19 pandemic causes a huge impact to global economy including people's income and purchasing power. Still, no one knows when this situation will end even though large amounts of vaccines have been distributed to many countries. Furthermore, in Indonesia, this has brought deflation which triggered by falling prices in several sectors. Some of the biggest affected sectors are food, beverages and also transportation. There is an assumption that basic needs producers such as F\&B and pharmacies will recover faster because people mostly spend money for their basic needs and do savings for the rest.

As we know, MSMEs give a big contribution to GDP. But, during this pandemic many MSMEs are permanently closed and some are still operating with lower income. As a result, an increase in the unemployment rate was carried out along 2020 and doesn't rule out the possibility in 2021. The contribution of MSMEs is very important to the country so that recovery is very urgently needed. Information and technologies used to make solutions are the keys to keep survive. These technologies including digital platforms which are tended to make MSME growth better than conventionally done. However, not all MSMEs can keep up this way easily due to various difficulties at financial or any other factors. Besides, electronic trade companies which are so famous and friendly-used nowadays should give mentoring and maintenance to digitize MSMEs.

With this pandemic that affects in both microeconomics and macroeconomics, government should take control so that Covid-19 cases can be minimalized and gain public trust for economic recovery. By a stimulus in consumption growth, purchasing power will prevent Indonesia from an economic recession. In the other hand, this kind of recovery should be understood before that will not give immediately impacts to some sectors. The government for seriously has prepared rescue scheme for MSMEs through social assistance, tax incentives and relaxations, credit restructuring, etc. These have been done transparently and accountably as priorities to boost economic growth remembering there are a lot of MSMEs in Indonesia.

In this digital era, technologies are being used to ease people's work. For example, technologies are used to produce food and beverage and also take roles in packaging to keep maintain the products. Other than that, technologies such as internet can be used for business, social interaction, finance, health care and education. Entrepreneurs who experienced difficulties in obtaining capital services from bank can use these technologies to access digital storages and financial services via smartphones which are very affordable by all levels of society. The 
internet itself is expected not to only be seen from platforms but also help MSMEs to play a bigger role in domestic supply chain to reduce imported goods. Besides, the opportunities to drive the internet economy and support the productivity can be enlarged by using the digital financial services. MSMEs recovery can overcome poverty and unemployment. Therefore, the government takes action and effort to direct, guide, protect, foster and encourage this sector during pandemic which happened for a year already. As mentioned before, all life aspects can be reached easier by using e-commerce. MSMEs are also able increase competitiveness and only require high creativity and knowledge of digitalization concept to stream goods and services. These have bigger advantages such as controlling market and consumers compare to modern retail which actually have many rules. Controlling market means as a tester point, both to test consumers' willing to the products or to test the potential location.

In fact, the number of MSMEs that have joined the digital ecosystem is still relatively small. Many solutions and innovation are needed to solve some problems faced by business actors which still covered structurally. MSMEs partnership is one of the government efforts to resolve various kind of problems like gaps between groups, income, employment and expanding economic business and giving contribution in national economy. Every MSME must be able to personalize their digital tools and being open to the related communities, to work on local advantages so that it can be more competitive in domestic and international market continuously. 